\title{
R-S recall and recognition as functions of stimulus and response meaningfulness'
}

JOHN SEDIVY AND DONALD H. KAUSLER

SAINT LOUIS UNIVERSITY

Meaningfulness ( $M$ as defined by association value of nonsense syllables) for both $S$ and $R$ components of paired associates was related to $R-S$ recall and recognition. $R-S$ recall was significantly related to $S m$ but not to $R M$. Neither $S M$ nor $R M$ had a significant effect on $R-S$ recognition. The results were interpreted as evidence against an intratrial rehearsal view of R-S learning.

Numerous studies have indicated that S-R pairedassociate learning is a function of meaningfulness (M) for both the $\mathrm{S}$ and $\mathrm{R}$ components, but with the effect being more pronounced for RM than for SM. Considerably less information is available relating both SM and RM to R-S learning. Cassem \& Kausler (1962) reported a direct monotonic effect for SM on R-S acquisition, but they did not vary RM concomitantly. Two studies in which SM and RM were varied simultaneously obtained conflicting results. Hunt (1959), in a factorial study employing disyllabic words as $\mathrm{S}$ and $\mathrm{R}$ components of high (H) and low (L) M, found a pronounced positive effect for SM but a much weaker positive effect for RM. On the other hand, Cautela (1965), in a nonfactorial study that departed in several important ways from most other paired-associate studies (including the use of heterogeneous materials to manipulate $\mathrm{M}$-nonsense syllables for LM and words for $\mathrm{HM}$ ), found a greater positive effect for RM than for SM. As a further test of the relative effects of SM and $R M$ on $R-S$ learning, the present study, like that of Hunt, employed a factorial design with HM and LM nonsense syllables as the $S$ and $\mathbf{R}$ components. R-S learning was measured by both the recall and the recognition of $S$ components.

Method 2

The Ss were 80 undergraduate students. They were assigned alternately to the four conditions $(N=20)$ of the 2 by 2 factorial design resulting from two levels of $M(H$ and $L)$ as varied in both the $S$ and $R$ components of a paired-associate list. Thus the four conditions, defined in terms of S-R M combinations, were $\mathrm{HH}, \mathrm{HL}, \mathrm{LH}$, and LL.

The $\mathrm{H}$ and $\mathrm{L}$ syllables were selected from the 80 $100 \%$ and $0-20 \%$ ranges, respectively, of Archer's (1960) norms. There were six paired associates in each list and intra-list similarity of letter content was minimized as much as possible. Following practice on a warm-up list, the pairs on the experimental lists were projected onto a small screen by a Carousel projector. The blocking or recall method was employed, with alternating study and test trials. During the study trials each pair was exposed for 2 sec. Each test trial was for 30 sec.; during this period $S$ was handed a sheet of paper listing the six $\mathrm{S}$ components and was instructed to write the $\mathrm{R}$ components in juxtaposition to the appropriate $\mathrm{S}$ components. Practice continued to a criterion of one perfect $S-R$ test trial. Immediately after the last $S-R$ test trial one 30 sec. $R-S$ recall trial was given in which the $\mathrm{R}$ components were listed on a sheet of paper and $S$ wrote down the $S$ component associated with each $\mathrm{R}$ component. Finally, a R-S recognition trial was given following precisely the procedure of Leicht \& Kausler (1965).

\section{Results and Discussion}

Summary data for trials to $S-R$ criterion, $R-S$ recall (number of $\mathrm{S}$ components correctly spelled), and R-S recognition (number of $\mathrm{S}$ components correctly identified) are given in Table 1 . For trials to $\mathrm{S}-\mathrm{R}$ criterion an analysis of variance yielded a highly significant positive effect for $\mathrm{RM}(\mathrm{F}, 25.13 ; \mathrm{df}, 1 / 76 ; \mathrm{p}<.001)$ and a significant positive effect for $\mathrm{SM}$ (F, 6.34; df, $1 / 76$; $p<.02)$. The SM by RM interaction effect was clearly not significant $(F<1)$. The analysis of variance for $R-S$ recall yielded a highly significant positive effect for SM ( F, 24.44; df, 1/76; $p<.001$ ). However, neither the main effect for RM nor the SM by RM interaction effect approached significance ( $F, 1.38 ; \mathrm{df}, 1 / 76 ; \mathrm{p}>.20$ and $F<1$, respectively). An analysis of covariance with trials to $S-R$ criterion as the adjusting variable failed to make an appreciable difference on the effects of $S M$ and $R M$ on $R-S$ recall. The averaged withingroup $r$ trials to $S-R$ criterion and amount of recall was only -.01 . Neither of the main effects nor the interaction effect approached significance for the R-S recognition measure (all ps $>$.10).

The present results are therefore in agreement with Hunt's earlier findings obtained with words rather than nonsense syllables as $S$ and $R$ components. SM seems to be a more potent variable related to $R-S$ recall than is RM. However, neither SM nor RM had an appreciable

Table 1. Summary Data for Trials to S-R Criterion, R-S Recall Scores, and R-S Recognition Scores

\begin{tabular}{lrrrrrrr} 
& \multicolumn{8}{c}{$\begin{array}{c}\text { Measures } \\
\text { Condition }\end{array}$} & \multicolumn{9}{c}{ S-R Trials } & \multicolumn{2}{c}{ R-S Recall } & \multicolumn{2}{c}{ R-S Recognition } \\
\hline & Mean & SD & Mean & SD & Mean & SD \\
\cline { 2 - 7 } & 6.65 & 4.45 & 3.50 & 1.50 & 5.10 & .85 \\
HH & 16.70 & 9.15 & 2.90 & 1.77 & 4.75 & .96 \\
HL & 11.45 & 9.23 & 1.70 & 1.38 & 4.90 & .85 \\
LH & 21.80 & 13.21 & 1.55 & .89 & 4.55 & 1.39 \\
LL & & & & &
\end{tabular}


effect on $\mathrm{R}-\mathrm{S}$ recognition when $\mathrm{S}-\mathrm{R}$ acquisition was taken to mastery of the list. Leicht \& Kausler (1965) had previously failed to find an effect for SM on R-S recognition. The present results corroborate this finding and, in addition, suggest that RM may also be unrelated to $\mathrm{R}-\mathrm{S}$ recognition.

These results are contrary to the interpretation of $\mathrm{R}-\mathrm{S}$ learning in terms of intratrial rehearsal that was recently offered by Wollen \& Gallup (1965) and thus provide some indirect support for an associative symmetry interpretation of $\mathrm{R}-\mathrm{S}$ learning. If $\mathrm{R}-\mathrm{S}$ recall is the product of S-R-S-R-S-R intratrial rehearsal, as proposed by Wollen and Gallup, the effect of RM on $\mathrm{R}-\mathrm{S}$ recall would be expected to be as pronounced as the effect of SM. Because of the greater ease of pronunciation and greater degree of prior integration, $\mathrm{R}$ components of HM should generate considerably more S-R-S-R-S-R rehearsal during the study trials than $R$ components of low $\mathrm{M}$, thereby leading to greater $\mathrm{R}-\mathrm{S}$ recall scores. This was not found in the present study.

Continued from page 228 .

fastest for the $40 \mathrm{db}$ group (as test signals were at or above $\mathrm{AL}$ ), slowest for the $100 \mathrm{db}$ group (test signals were at or below $A L)$, and intermediate for the silence group."

The above statement makes the critical assumption that Ss do not adapt to silence. If the contrary assumption is made, the AL for the silence-adapted group should be lower than those of the other two groups during the $\mathrm{RT}$ trials and the relative signal intensity greatest. The groups would be ordered on a relative signal intensity dimension (geometric mean intensity of the RT signals, at $70 \mathrm{db}$, minus pre-RT AL) as follows:

$\begin{array}{ccr}\text { Pre-test AL } & \text { Test Signal } & \text { Difference } \\ \text { Silence } & 70 \mathrm{db} & \text { circa } 60 \mathrm{db} \\ 40 \mathrm{db} & 70 \mathrm{db} & 30 \mathrm{db} \\ 100 \mathrm{db} & 70 \mathrm{db} & -30 \mathrm{db}\end{array}$

If this is the case, an alternative explanation of Murray and Kohfeld's findings is necessary. The one suggested here is afforded by the Bevan-Adamson (1962) model for reinforcement. This model assumes a tensional intermediary between the difference, intensitive input minus $\mathrm{AL}$, and resulting performance. Accordingly, there would be a direct relationship between relative signal intensity and presumed tension level for the groups in Murray and Kohfeld's study.

\section{References}

Archer, E. J. A re-evaluation of the meaningfulness of all possible CVC trigrams. Psychol. Monogr., 1960, 74, No.10, Whole No. 497.

Cassem, N., \& Kausler, D. H. Supplementary report: Effects of stimulus association value and exposure duration of R-S learning. J. exp. Psychol., 1962, 64, 94.

Cautela, J. R. The effect of $S$ meaningfulness and $R$ meaningfulness on R-s learning. J. Psychol., 1965, 61, 123-126.

Hunt, R. G. Meaningfulness and articulation of stimulus and re sponse in paired-associate learning and stimulus recall. $J$. exp. Psychol., 1959, 57, 262-267.

Leicht, K. L., \& Kausler, D. H. Supplementary report: Functional stimulus learning as related to degree of practice and meaningfulness. J. exp. Psychol., 1965, 69, 100-101.

Wollen, K. A., \& Gallup, G. G., Jr. R-S recall as a function of opportunity for intratrial rehearsal. Psychon. Sci., 1965, 3 , 157-158.

\section{Notes}

1. Based on a Master's thesis by J. S. under the direction of D. H. K.

2. An additional two level variable in the study was type of instructions. However, the effect of this variable, and its interactions with other variables, was extremely slight on all criterial measures and was omitted from the present study.
A further assumption of the Bevan-Adamson model is that tension-level is curvilinearly related to performance in the form of an inverted $U$, an assumption well supported experimentally (e.g. Courts, 1939, Shaw, 1956, Yerkes, \& Dodson, 1908). On the basis of it, it would be expected that the group pre-adapted to $40 \mathrm{db}$ would represent an intermediate-and possibly optimal-tension level and should show the fastest $\mathrm{RT}$, whereas the other two groups, representing high and low tension levels, should show less efficient performance. This expectation is in accord with the findings of Murray and Kohfeld.

\section{References}

Bevan, W., \& Adamson, R. Reinforcers and reinforcement: Their relation to maze performance. J. exp. Psychol., 1960, 59, 226-232.

Bevan, W., \& Adamson, R. Internal referents and the concept of reinforcement. In N. F. Washburne (Ed.), Decisions, values, and groups. Vol. 2. New York: Pergamon, 1962.

Black, R., Adamson, R., \& Bevan, W. Runway behavior as a function of apparent intensity of shock. J. comp. physiol. Psychol., $1961,54,270-274$.

Courts, F. A. Relations between experimentally produced muscular tension and memorization. J. exp. Psychol., 1939, 25, 235-256.

Murray, H., \& Kohfeld, D. Role of adaptation level in stimulus intensity dynamism. Psychon. Sci., 1965, 3, 439-440.

Shaw, W. A. Facilitating effects of induced tension upon perception span for digits. J. exp. Psychol., 1956, 51, 113-117.

Yerkes, R., \& Dodson, J. The relation of strength of stimulus to rapidity of habit formation. J. comp. Neural. Psychol., 1908 $18,459-482$. 